\title{
Anticoagulant Therapy in Some Diseases Related with Arteriosclerosis
}

\author{
Kiku NAKAO \\ Department of Medicine, Gunma University, \\ School of Medicine, Maebashi
}

Only recently, it is becoming common in Japan, to use anticoagulants to prevent recurrent thrombo-embolic accidents frequently encountered during a time course of various kinds of diseases related with arteriosclerosis, especially in patients with myocardial infarction, with coronary insufficiency or with cerebrovascular insuffciency.

This paper will concern with results obtained through our clinical experiences in these respects in 77 cases in a total number, and also with some results from our experimental attempts to approach a mechanism of actions of anticoagulants on preventing recurrences of ischemic attacks.

\section{Clinical Observation}

1. Type of Anticoagulants Used and Methods of Control

Twenty-four patients were treated with indione, 43 with sintrom, 11 with warfarin and only two with heparin. In the last two patients with acute myocardial infarction, heparin was used solely at the early stage of attack to cover a lag time of peroral administration of anticoagulants.

The one-stage method of prothrombin determination of Quick was used in all cases, and also the thrombotest was employed concomitantly recently. It seems reasonable to keep a prothrombin activity within a range from 15 to 35 per cent of a normal level.

Tests such as determination of Factors V and VII, thromboplastin generation test, platelet-counts, platelet-adhensiveness and retractibility of blood coagula were carried out at a given time interval or when indicated. 
2. Myocardial Infarction

A number of patients treated with anticoagulants is 29 , male 23 and female 6 , and that of a control group is 24 , male 15 and female 9, which comprises patients with myocardial infarction observed in our clinic during a corresponding period of time.

Age distribution of the two groups falls in a range from 40 to 69 .

A number of patients in whom anticoagulant therapy was started within six weeks after the first attack of myocardial infarction is 10 , and that of the corresponding control group is 8 . Deaths occurred in only one of the treated patients and in 2 of the control, respectively. A small number of deaths encountered in these two groups of patients leads us to consider that our observation materials might probably miss a lot of early and severe patients with myocardial infarction. Therefore, it needs further accumulation of early and severe cases, to make an accurate statistical analysis for effectiveness of this therapy in an early stage of myocardial infarction. The number of patients treated over a period of three months sums to 20 , a discontinued group of patients, who abandoned regimen after varying periods of treatment from 1 to 12 months, comprises 11, and a control group 19. Sex and age distributions appear at the upper part of Table 1. Durations of treatment and observation are shown by the number of months in the middle of Table 1.

Patients dying while on regimen or on observation.

The number of deaths is only one in the treated group, five in the discontinued group, which occurred eight months in average after suspension, and seven in the control. In respect of causes of deaths, one died from recurrent myocardial infarction in the treated group, four from recurrent myocardial infarction and one from cardiac insufficiency in the discontinued group, and 5 from recurrent myocardial infarction and 2 from cardiac insufficiency in the control, respectively, as shown in Table 1.

Incidences of recurrences of myocardial infarction are twice in the treated, 4 times in the discontinued, and 5 times in the control group. Other thrombo-embolic episodes were not clinically observed in all patients regardless treated or not.

The results above stated seem to indicate a possibility that a 
Table 1. Results of Long-term Treatment in Myocardial Infarction

\begin{tabular}{|c|c|c|c|c|c|}
\hline & & & $\begin{array}{l}\text { Treated } \\
\text { Group }\end{array}$ & $\begin{array}{l}\text { Discontinued } \\
\text { Group }\end{array}$ & $\begin{array}{l}\text { Control } \\
\text { Group }\end{array}$ \\
\hline \multicolumn{3}{|c|}{ Number of Cases } & 20 & 11 & 19 \\
\hline \multicolumn{3}{|c|}{ Male/Female } & $17 / 3$ & $7 / 4$ & $12 / 7$ \\
\hline \multicolumn{3}{|c|}{ Mean Age } & $55.0(41-73)$ & $61.6(36-73)$ & $59.6(46-71)$ \\
\hline \multicolumn{2}{|c|}{ Treatment Months } & Total & $610 / 30.5$ & $45 / 4$ & 0 \\
\hline \multicolumn{2}{|c|}{$\begin{array}{l}\text { Observation Months } \\
\text { Without Treatment }\end{array}$} & Mean & 0 & $193 / 17.5$ & $494 / 26$ \\
\hline \multirow{2}{*}{ Deaths } & \multicolumn{2}{|c|}{ No. of Cases } & 1 & 5 & 7 \\
\hline & \multicolumn{2}{|r|}{$\%$} & 5 & 45.4 & 36.8 \\
\hline \multirow{2}{*}{$\begin{array}{l}\text { Recurrence } \\
\text { of lnfarction }\end{array}$} & \multicolumn{2}{|c|}{ No. of Cases } & 2 & 4 & 5 \\
\hline & \multicolumn{2}{|c|}{$\%$} & 10 & 36.3 & 23.6 \\
\hline \multirow{2}{*}{$\begin{array}{l}\text { Other Throm- } \\
\text { boembolism }\end{array}$} & \multicolumn{2}{|c|}{ No. of Cases } & 0 & 0 & 0 \\
\hline & \multicolumn{2}{|c|}{$\%$} & 0 & 0 & 0 \\
\hline \multirow{2}{*}{$\begin{array}{l}\text { Cause of } \\
\text { Death }\end{array}$} & \multicolumn{2}{|c|}{$\begin{array}{l}\text { Recurrence } \\
\text { of Infarction }\end{array}$} & 1 & 4 & 5 \\
\hline & \multicolumn{2}{|c|}{$\begin{array}{l}\text { Cardiac } \\
\text { Insufficiency }\end{array}$} & 0 & 1 & 2 \\
\hline
\end{tabular}

long-term anticoagulant therapy for myocardial infarction could be fairly effective in reducing a mortality rate and an incidence of recurrence of myocardial infarction. However, my feeling is that it is seriously necessary to accumulate much more numbers of patients sufficient to be fit for a statistical analysis.

\section{Angina Pectoris}

Angina pectoris has a considerably wide meaning, but in our case a somewhat restricted criterion to select patients was provided as follows: clinically clear symptoms and signs due to coronary insufficiency and ST-T changes in electro-cardiograms, including a two step test, and lacking of any findings indicating a presence of myocardial infarction.

The number of patients complaining of angina pectoris and receiving anticoagulant therapy sums to 22 , male 14 and female 8 , and the number of control group 19, male 17 and female 2. Sex and age distribution is shown in Table 2. 
Table 2. Effect of Anticoagulants on Incidence of Angina-Attack

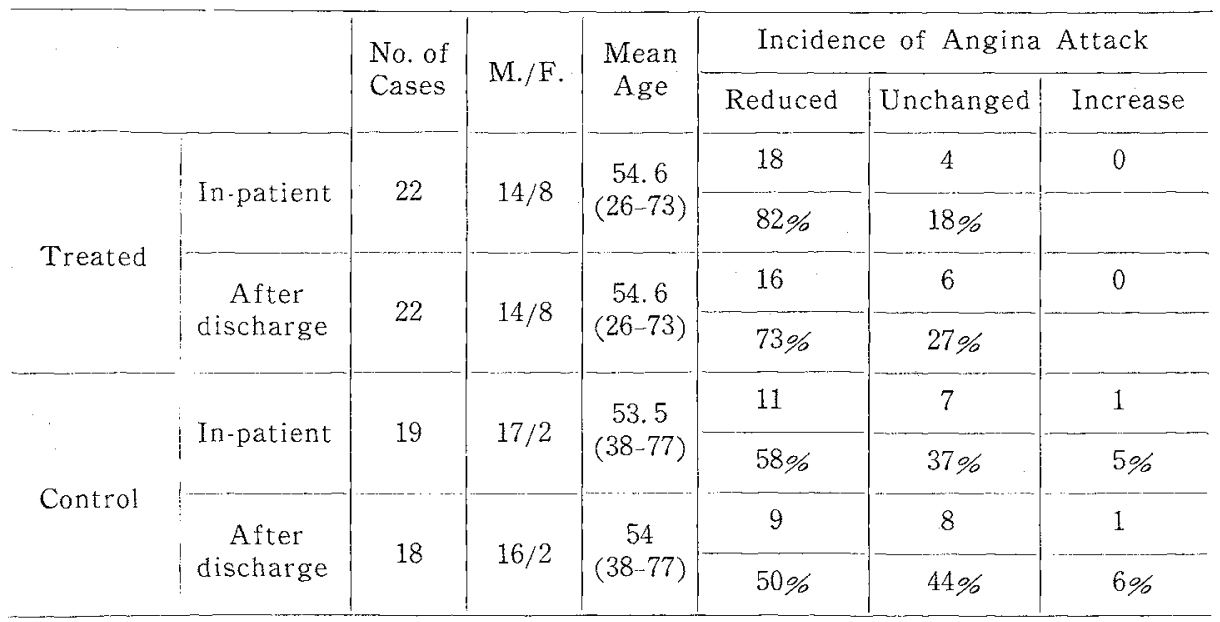

In respects of prognosis of these patients, one death from myocardial infarction in the treated group, two deaths in 13 discontinued group (one from myocardial infarction and the other from cerebral hemorrhage), and four deaths in 19 patients of the control group (2 from myocardial infarction, one from cerebral hemorrhage and other one).

The number of patients in whom myocardial infarction developed during a period of therapy and/or observation, is two in the treated, one in the discontinued and three in the control group. A statistical analysis of this material seems to be difficult to ascertain whether anticoagulant therapy for angina pectoris could be effective in reducing a mortality rate and in preventing development of myocardial infarction, because of too small numbers both of patients treated and of the control group, and also of a marked discrepancy of the observation months between them. However, the results obtained revealed that a long term anticoagulant therapy could be considerably effective in reducing incidence of anginal attacks during a hospitalized period and almost equally even after discharge, as compared with that of the control (Table 2).

4. Cerebrovascular Lesions

This group comprises mainly such patients as complaining of transient ischemic attacks or cerebrovascular thrombo-embolic lesions including cerebral softening caused probably by arteriosclerosis. It 
Table 3. Results of Anticoagulant Treatment in Cerebral Vascular Lesion

\begin{tabular}{|c|c|c|c|}
\hline & & Treated & Control \\
\hline \multicolumn{2}{|c|}{ No. of cases } & 11 & 11 \\
\hline \multicolumn{2}{|c|}{ Male/Female } & $10 / 1$ & $6 / 5$ \\
\hline \multicolumn{2}{|c|}{ Average age } & $57.8(42-70)$ & $59.7(43-75)$ \\
\hline \multirow{2}{*}{$\begin{array}{c}\text { Treatment or } \\
\text { observation months }\end{array}$} & Total & 327.3 & 433.6 \\
\hline & Average & 29.8 & 31.3 \\
\hline \multirow{2}{*}{ Deaths } & No. of cases & 1 & 6 \\
\hline & $\%$ & 9.1 & 54.5 \\
\hline \multirow{3}{*}{ Cause of death } & Bleeding & 1 & 0 \\
\hline & Thrombo-emb. & 0 & 3 \\
\hline & Others & 0 & 3 \\
\hline \multirow{4}{*}{$\begin{array}{l}\text { Incidence of } \\
\text { thrombo-embolism }\end{array}$} & Cerebral & 1 & 7 \\
\hline & Myocardial & 0 & 1 \\
\hline & Acvi.* & 2 & 1 \\
\hline & Others & 0 & 0 \\
\hline
\end{tabular}

Acvi.*: Attack of cerebral vascular insufficiency.

is widely accepted that it is occasionally difficult to discriminate stroke due to cerebral softening from that due to cerebral hemorrhage.

Our criteria to make a diagnosis of cerebral softening are as follows: relatively high-aged, no previous episodes of hypertension, clinical evidences of generalized arteriosclerosis, mild occurrence of stroke lacking of any symptoms and signs ensued from elevation of cerebrospinal pressure and also of any severe disturbances of consciousness at the time of stroke, etc.

The number of patients who received anticoagulant therapy sums to 26 , male 24 and female 2 , and age distribution ranges from 50 to 79 . The number of a control is 14 , male 7 and female 7 and age distribution falls within a range from 50 to 69 . The period of observation in 26 cases amounts to 740.3 months in total, and to 28.4 months in average, but a net period of therapy is 250 months, 10 months in average. The number of patients who abandoned 
regimen is 19 . The period of observation in patients of the control group sums to 438.6 months in total, 31.3 months in average.

Only 11 among the treated patients received continuously regular regimens over a period of three months, and the number of the corresponding control group is 11 . The total observation month of the treated and control group sums to 327.3 months, 29.8 months in average, respectively. Deaths occurred in one of the treated and in 6 of the control group. Incidences of ischemic accidents during the courses of observation were one cerebral stroke and 2 transient minor attacks in the treated group, in contrast to 7 cerebral strokes, one minor ischemic attacks and one myocardial infarction in the control (Table 3).

This fact seems to indicate some possibly favorable effects of anticoagulant therapy on these kinds of cerebrovascular lesions. However, it is difficult to ascertain it, because of the variableness of severity of vascular lesions in each individual of our materials and of a paucity of numbers of patients observed. Our experiences, however, present a clear evidence indicating that a long term therapy with anticoagulants show fairly good effects in reducing incidence of recurrent minor ischemic attacks in patients complaining of transient ischemic accidents probably due to cerebral arteriosclerosis.

However, whether any favorable effectiveness of this kind of treatments for cerebral thrombo-embolism, including manifested cerebral softening, could be expected or not, still remains a subject of controversy.

5. Changes of Various Coagulant Factors due to a Long Term Anticoagulant Therapy

In patients treated with anticoagulants for periods varying from one to six years, activities of various kinds of coagulation factors, including functions of platelets; were examined.

Results obtained are in good agreements with that have already been presented from many laboratories. Whole blood coagulation was normal, and reduced activity of serum factors (Factors IX and $X$ ), normal activity of plasma factor (Factor VIII), and unchanged platelet function in thromboplastin generation test were observed. Prolonged one-stage prothrombin time, depressed amount of prothrombin and markedly reduced activity of Factor VII complex were 
demonstrated, but any detectable changes neither in activity of Factor $V$ nor in amount of fibrinogen.

In spite of many recent advocations about possible changes of

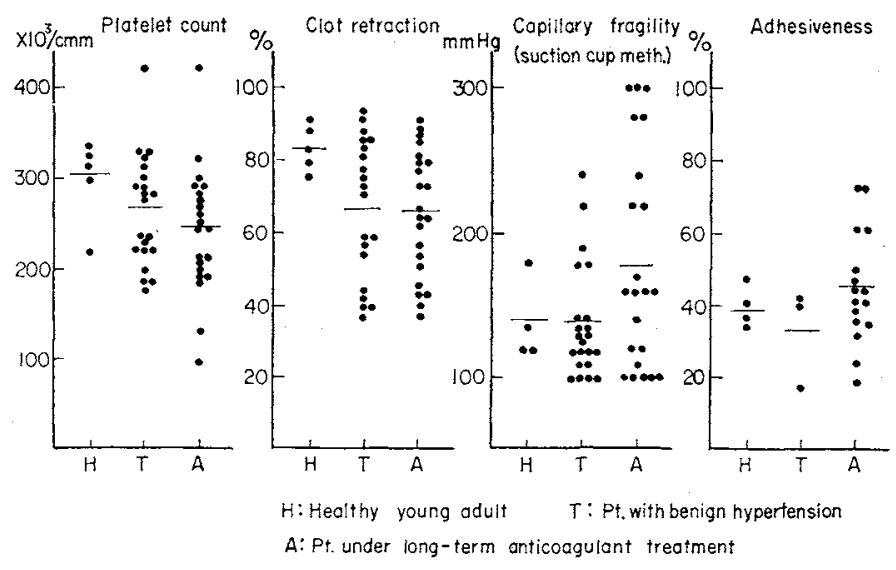

Fig. 1. Results of various tests on platelet function.

Table 5. Complications

\begin{tabular}{|c|c|c|c|c|c|c|}
\hline \multirow{2}{*}{\multicolumn{2}{|c|}{$\begin{array}{l}\text { Various Kind of } \\
\text { Complications }\end{array}$}} & \multirow{2}{*}{$\begin{array}{l}\text { No. of } \\
\text { Accid. }\end{array}$} & Major & Minor & In & Out \\
\hline & & & \multicolumn{2}{|c|}{ Hemorrhage } & \multicolumn{2}{|c|}{ Patients } \\
\hline \multirow{8}{*}{ 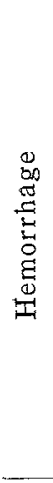 } & Petechia & 19 & & 19 & 4 & 15 \\
\hline & Gum & 7 & & 7 & 2 & 5 \\
\hline & Submucosal & 6 & & 6 & & 6 \\
\hline & Epistaxis & 7 & & 7 & 1 & 6 \\
\hline & Macrohematuria & 2 & 2 & & & 2 \\
\hline & G. I. Tract & 2 & 2 & & 1 & 1 \\
\hline & Peritoneal & 1 & 1 & & & 1 \\
\hline & Cerebral & 2 & 2 & & 2 & \\
\hline & Exanthema & 3 & & & & 3 \\
\hline & Others & 0 & 0 & 0 & 0 & 0 \\
\hline & $\begin{array}{l}\text { Incidence of } \\
\text { Accidents }\end{array}$ & & 7 & 39 & 10 & 39 \\
\hline \multirow{2}{*}{\multicolumn{2}{|c|}{$\begin{array}{l}\text { Patients with } \\
\text { Complication }\end{array}$}} & No. & 7 & 27 & 10 & 27 \\
\hline & & $\%$ & 9 & 36 & 13 & 35 \\
\hline
\end{tabular}


platelet functions due to a long term anticoagulant therapy, our observation could not clearly confirm this thesis, as shown in Fig. 1.

6. Incidence of complications

Most frequent complications encountered during a period of long term anticoagulant therapy are naturally thought to be various kinds of hemorrhages. As appeared in Table 4, minor hemorrhages such as petechia, gum-bleeding, submucosal bleeding, nose-bleeding, etc. appeared 39 times in 27 patients, and moderate or gross hemorrhages such as macro-hematuria, gastrointestinal bleeding, cerebral hemorrhage and bleeding into the peritoneal cavity occurred 7 times in 7 patients, three of whom died, two from cerebral hemorrhage and one from uremia probably caused by severe hematuria. Incidence of hemorrhagic complications is about three times higher in outpatients than in inpatients (Table 4).

On incidence of hemorrhagic complications in our patients observed is considerably comparable to that reported by other investigators.

\section{Some Experimental Approaches to Mechanism of Actions of Anticoagulant Therapy in Arteriosclerosis}

1. Experimental Studies of Effects of Anticoagulants on Thromboplastic Activity of Blood Vessels and on Development of Atherosclerosis in Rabbits Fed with Lanolin

It has been accepted that the arterial walls of man and animals possess thromboplastic activity. On the other hand, a hypothesis for a possible causal relationship of fibrin deposition into arterial walls or of intraarterial thrombi with development of arteriosclerosis has been one of the subjects of various controversy for a long time. Therefore, attempts were made to study on the questions whether anticoagulants could affect a thromboplastic activity of blood vessels themselves, and consequently on development of atherosclerosis in rabbits fed with lanolin diet.

For determination of thromboplastic activity of blood vessels, the method described by Stevenson et al. was employed. On the other hand, the arterial walls taken from rabbits fed with lanolin and also from human autopsy materials of various ages from fetus 
Table 5. Method for the Determination of Thromboplastic Activity of Tissue Extract from Aorta

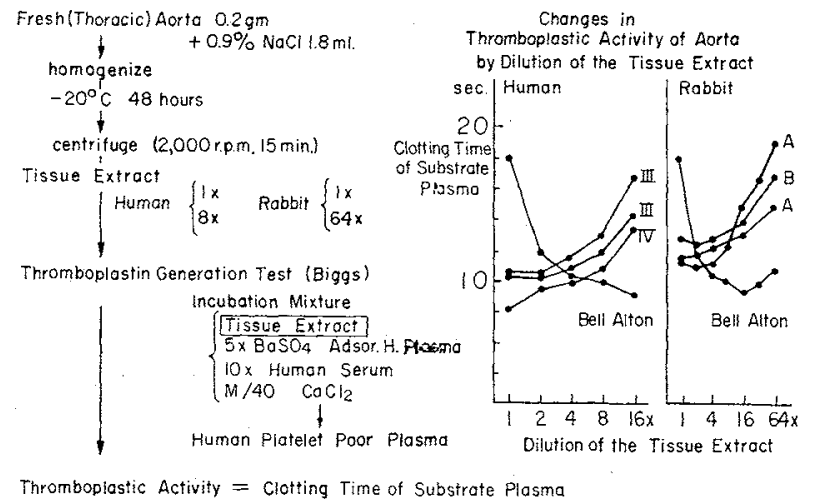

to 70 years old were classified into four groups according to the grade of histological findings indicating arteriosclerotic changes, especially taking into consideration the grade of fibrinous thickening of the intima and of lipid invasions into the intima and media, as shown in Fig. 2.

A thromboplastic activity of human blood vessels increased in good correlation with severity of arteriosclerotic changes, as shown on the left half of Fig. 2.

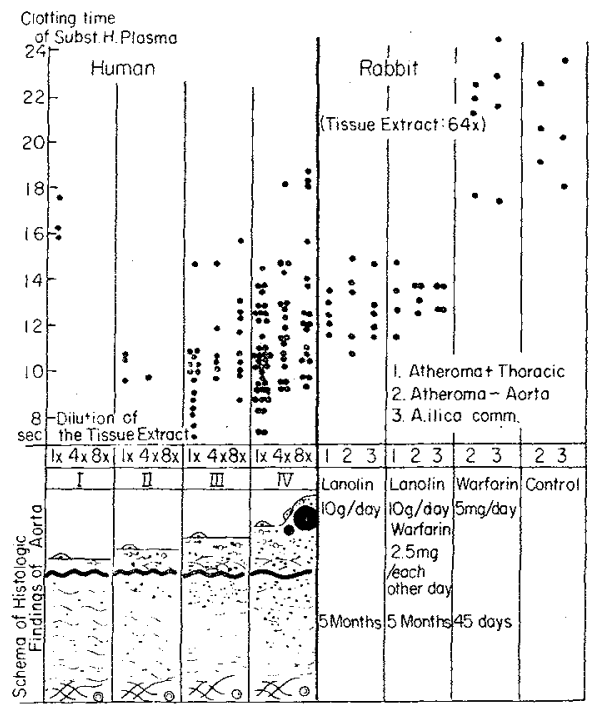

Fig 2 Thromboplastic activity of aorta. 
One group of rabbits (A Group) was fed with lanolin and ordinary diet, and another group (B Group) was fed with lanolin and ordinary diet added with proper dosage of warfarin, both for five months. And the results obtained from our animal experiments appear in the right half of Fig. 2.

Marked atheromatous changes were demonstrated in the aorta, coronary vessels and other arteries, especially notably at the sites of bifurcation on the arteries, showing no significant difference both macroscopically and histologically, between $A$ Group and B Group. And also a thromboplastic activity of blood vessels was augmented almost similarly both in A and B Group. No atheromatous changes were observed in any parts of blood vessels of control group. It is noteworthy to emphasize that a thromboplastic activity of blood vessels from control group showed less values than that of lanolin fed rabbits, regardless warfarin was given or not.

These facts strongly suggest that a long term administration of anticoagulants does affect neither development of atheromatous changes nor thromboplastic activity of blood vessels in any ways. However, it must be taken into consideration that this assumption is made on the bases of data obtained under somewhat peculiar conditions of rabbits such as being fed with a diet containing high amount of lanolin. However, one thing to be emphasized is that a long-term administration of anticoagulant does not show any effects on a thromboplastic activity of blood vessels even in normal rabbits.

2. Effects of Anticoagulant on Development of Experimental Arterial Thrombosis in Rabbits

In rabbits the bilateral femoral arteries were separated from the surrounding tissues and made narrow by ligation. Thereafter, a mixture of $0.2 \mathrm{ml}$. own whole blood and $0.2 \mathrm{ml}$. own serum was injected into the one sided artery at the proximal site of ligation, and the same amount of saline into the artery of another side. Then, the operation wounds were closed. All the procedures were done aseptically. After twenty four hours elapsed, occurrence of arterial thrombosis was observed in the site of serum injection in a rate of 80 per cent, whereas none in the artery of the opposite side.

In series of this experiment, a single injection with 750 units 
or more of heparin exactly thirty minutes prior to the serum injection completely prevent the development of arterial thrombosis, and also twice administrations of $2.5 \mathrm{mg}$. warfarin, fourty eight hours prior to and two hours behind the operation could completely inhibit development of thrombosis, when prothrombin activity was reduced below twenty per cent of a normal level, otherwise could develop. On the other hand, this experiment provided evidences indicating that neither heparin injection nor warfarin administration even in much more amounts, after thrombi had already developed, could affect the once formed arterial thrombi in any way.

Results obtained through the two kinds of our experiments can provide a possible and reasonable explanation for a mechanism of actions of anticoagulant therapy in patients with arteriosclerosis; namely anticoagulant therapy does not affect development of atherosclerosis in any ways, but can prevent further formation of arterial thrombi.

\section{Summary}

A small number of our treated patients and a paucity of well corresponding control group make it somewhat difficult to draw any statistically definitive conclusion on effectiveness of a long term anticoagulant therapy in various kinds of diseases closely related to. arteriosclerosis. I would like, however, to emphasize that good choice of indication for this treatment, well trained control of patients and good understanding and cooperation of patients can make this regimen to be more profitable beyond any questions. Furthermore, results of our animal experiments present partly clear evidence for reasonable explanation of favorable action of anticoagulant. therapy in patients with arteriosclerotic disorders.

\section{References}

1) Alexander, B. and Wessler, S.: A Guide to Anticoagulant Therapy. Circulation $24: 123,1961$.

2) Ambrus, C.M., Back, N. and Ambrus, J.L.: On the Mechanism of Thrombolysis by Plasmin. Circulation Research 10:161, 1962.

3) Astrup, T., Albrechtsen, O.K., Classen, M. and Rasmussen, K.: Thromboplastic and Fibrinolytic Activity of the Human Aorta. Circulation Res. 7: 967, 1959. 
4) Borchgrevink, C.F.: Long-term Anticoagulant Therapy in Angina pectoris and Myocardial Infarction. A clinical trial of intensive versus moderate treatment. Acta Med. Scandinav. Suppl. 359, 1960.

5) Borchgrevink, C. E.: Platelet Adhesion in vivo.in Patients with Bleeding Disorders. Acta Med. Scandinav. 170:231, 1961.

6) Carter, A. B.: Anticoagulant Treatment in Progressing Stroke. Brit. Med. J. 2: $70,1961$.

7) Constantinides, P. and Chakravarti, R. N.: Rabbits Arterial Thrombosis Production by Systemic Procedures. Arch. Pathol. 72: 197, 1961.

8) Duguid, J.B.: Thrombosis as a factor in the pathogenesis of aortic atherosclerosis. J. Path. Bact. $60: 57,1948$.

9) Friedman, M. and Byers, S. O.: Experimental Thrombo-Atherosclerosis. J. Clin. Invest. 40: 1139, 1961.

10) Grouch, S. N., McDevitt, E. and Wright I.S.: A Long-term Study of Cerebral Vascular Disease. Ann. Int. Med. 55: 358, 1961.

11) Hilden, T., Iversen, K., Raaschou, F. and Schwartz, M.: Anticoagulants in Acute Myocardial Infarction. Lancet 2: 327, 1961.

12) Isesi, O.D. and Benditt, E.P.: Genesis of Thrombi; Studies of their Fine Structure. Fed. Proc. 29: 133, 1961.

13) Koller, V.F.: Die Pathogenese der Thrombose und ihre therapeutischen Konsequenzen. Dtsch. Med. Wschr. 86: 1793, 1961.

14) Meyer, J.S.: Occlusive Cerebrovascular Disease. Pathogenesis and Treatment. Am. J. Med. $30: 577,1961$.

15) Moolton, S. E., Vroman, L. and Vroman, G. M.S. : Adhesiveness of Blood Platelets in Thromboembolism and Haemorrhagic Disorders. 11. Diagnostic and Prognostic Significance of Platelet Adhesiveness. Am. J. Clin. Path. 19: 814, 1949.

16) Murphy, E.A. and Mustard, J.F.: Coagulation Tests and Platelet Economy in Atherosclerotic and Control Subjects. Circulation 25:114, 1962.

17) Murphy, E. A. and Mustard, J.F.: Dicumarol Therapy. Some Effects on Platelets and their Relation to Clotting Test. Circulation Res. 8: 1187, 1960.

18) Mustard, J., Downie, H.G., Murphy, E.A. and Rowsell, H.C.: Lipids Platelets and Atherosclerosis in Blood Platelets. Henry Ford Hospital Intern. Symposium. 1960.

19) Nichol, E. S., Keyes, J. N., Borg, Coogan, T. J., Boehrer, J. J., Mullins, V. L., Scott, Th., Page, R., Griffith, G.C. and Massie, E.: Long-term Anticoagulant Therapy in Coronary Atherosclerosis. Am. Heart J. 55: 142, 1958.

20) O'Brien, J.R.: Fat Injection, Blood Coagulation and Atherosclerosis. Am. J. Med. Sci. 234 : 373, 1957.

21) Owren, A.A.: Long-term Dicumarol Therapy in Cardiovascular Diseases. Acta Med. Scandinav. Suppl. 287: 46, 1953.

22) Owren, P.A.: Thrombotest. A New Method for Controlling Anticoagulant Therapy. Lancet 2: 754, 1959.

23) Pascuzzi, Ch. A., Spittel, J.A., Thompson, J.H. and Owen, Ch. A.: Thromboplastic Generation Accelerator. A Newly Recognized Component of the Blood Coagulation Mechanism Present in Excess in Certain Thrombotic States. J. Clin. Invest. 40: 1006, 1961.

24) Pollard, J. W., Hamilton, M. J., Christensen, N. A. and Achor, R. W. P.: Problems Associated with Long-term Anticoagulant Therapy. Observations in 139 cases. Circulation 25:311, 1962.

25) Poole, J.C.F.: Factors Influencing the Formation of Artificial Thrombi. Throm- 
bosis and Anticoagulant Therapy. Edited by W. Walker, 1960.

26) Sherry, S., Titchener, A., Gottesman, L., Wasserman, P. and Troll, W.: The Enzymatic Dissolution of Experimental Arterial Thrombi in the Dog by Trypsin, Chymotripsin and Plasminogen Activators. J. Clin. Invest. 33: 1303, 1954.

27) Sise, H.S., Moschos, Ch. B., Gauthier, J. and Becker, R.: The Risk of Interrupting Long-term Anticoagulant Treatment. A Rebound Hypercoagulable State Following Hemorrhage. Circulation 24: 1137, 1961.

28) Stevensen, T. D., Schrodt, G. R. and Reed, L. M.: The Coagulant Properties of Normal and Arteriosclerotic Aortas. Am. J. Med. Sci. 241: 632, 1961.

29) Wessier, S., Reimer, S. M., Bloede, M. L., Nickles, M. and Szalai, B. J.: The Role of Human Coagulation Factors in Serum-induced Thrombosis. J. Clin. Invest. 39: 262, 1960.

30) Wright, I.S.: The Use of the Anticoagulants in the Treatment of Diseases of the Heart and Blood Vessels. Ann. Int. Med. 30: 80, 1949.

31) Wright, I.S.: The Use of Anticoagulants in Coronary Heart Disease. Circulation $22: 608,1960$. 